\title{
Antimetropia in a 10-year-old boy with unilateral tilted disc syndrome
}

This article was published in the following Dove Press journal:

Clinical Optometry

7 May 2014

Number of times this article has been viewed

\section{Shinji Makino}

Department of Ophthalmology, Jichi Medical University, Shimotsuke, Tochigi, Japan
Correspondence: Shinji Makino Department of Ophthalmology, Jichi Medical University,

33 I I-I Yakushiji, Shimotsuke,

Tochigi 329-0498, Japan

$\mathrm{Tel}+8 \mathrm{I} 285587382$

Fax +8I 285448365

Email makichan@jichi.ac.jp
Abstract: Antimetropia is a condition in which one eye is myopic, while the fellow eye is hyperopic. This report describes a case of antimetropia associated with unilateral tilted disc syndrome. A 10-year-old boy presented with the complaint of diminished vision for distant objects in his right eye for several months. His uncorrected distance visual acuity was 0.15 in the right eye and 1.0 in the left eye. Best corrected visual acuity was 1.0 , with $-6.00 \mathrm{D} /-2.00$ $\mathrm{D} 170^{\circ}$ in the right eye and $+1.50 \mathrm{D}$ in the left eye. The cover test revealed right esotropia and hypertropia. Bifoveal fixation was achieved using a 14 prism diopter (PD) base at $220^{\circ}$ in the right eye. Fundus examination revealed a tilted disc with inferior staphyloma in the right eye, but no abnormal findings were observed in the left eye. In addition, the patient occasionally experienced diplopia under casual viewing conditions. A cycloplegic refraction revealed $-6.00 \mathrm{D} /-2.00 \mathrm{D} 170^{\circ}$ in the right eye and $+1.50 \mathrm{D} /-2.00 \mathrm{D} 5^{\circ}$ in the left eye. Thus, prism glasses were prescribed. While wearing the prism glasses, the patient has shown no diplopia and maintains good binocular function.

Keywords: amblyopia, strabismus, anisometropia, staphyloma

\section{Introduction}

Anisometropia is a common condition characterized by an interocular difference in refractive error. Small degrees of anisometropia are inconsequential, but higher degrees are often accompanied by amblyopia in the more ametropic eye. In contrast, a significant degree of antimetropia, in which one eye is myopic and the fellow eye is hyperopic, is quite rare. ${ }^{1-4}$

Tilted disc syndrome is a relatively common congenital anomaly, occurring in $0.4 \%$ to $3.5 \%$ of the population, which consists of the rotation of the disc as a clockwise or counterclockwise rotation. ${ }^{5,6}$ Associated findings typically include an obliquely directed long axis of the disc, a posterior staphyloma, and situs inversus. The most important correlate of these lesions is a myopic astigmatism, most pronounced in the region of the staphyloma, and superotemporal or bitemporal visual field depression. ${ }^{5-8}$ The aim of this study was to report a case of a 10 -year-old boy with antimetropia associated with unilateral tilted disc syndrome.

\section{Case report}

A 10-year-old boy presented with the complaint of diminished vision for distant objects in his right eye for several months. There was no significant ocular or medical history, and birth history was normal. His uncorrected distance visual acuity was 0.15 in the right eye and 1.0 in the left eye. Best corrected visual acuity was 1.0 with $-6.00 \mathrm{D} /-2.00$ 
$\mathrm{D} 170^{\circ}$ in the right eye and $+1.50 \mathrm{D}$ in the left eye. The keratometry readings were $43.00 \mathrm{D}$ at $172^{\circ} / 45.75 \mathrm{D}$ at $82^{\circ}$ in the right eye and $43.25 \mathrm{D}$ at $10^{\circ} / 46.75 \mathrm{D}$ at $100^{\circ}$ in the left eye. The cover test revealed right esotropia and hypertropia. Bifoveal fixation was achieved using a 14 prism diopter (PD) base at $220^{\circ}$ in the right eye. Fundus examination revealed a counterclockwise rotated disc with inferior staphyloma in the right eye (Figure 1A), but abnormal emergence of the retinal vessels (situs inversus) was not detected in the right optic disc. In contrast, no abnormal findings were observed in the left eye (Figure 1B). Ultrasonic B-scan echography (UD-8000; Tomey Corp, Nagoya, Japan) revealed inferior staphyloma in the right eye (Figure 2A), but no abnormal findings were observed in the left eye (Figure 2B). The axial length was $25.8 \mathrm{~mm}$ in the right eye and $23.2 \mathrm{~mm}$ in the left eye. The condition was diagnosed as antimetropia due to tilted disc syndrome. In addition, the patient occasionally experienced diplopia under casual viewing conditions. A cycloplegic refraction using $1 \%$ solution of atropine sulfate (three times per day for 7 days) disclosed $-6.00 \mathrm{D} /-2.00 \mathrm{D} 170^{\circ}$ in the right eye, and $+1.50 \mathrm{D} /-2.00 \mathrm{D} 5^{\circ}$ in the left eye. Prism glasses, with $7 \mathrm{PD}$ base at $220^{\circ}$ in the right eye and $7 \mathrm{PD}$ base at $40^{\circ}$ in the left eye, were prescribed. While wearing the prism glasses, the patient has shown no diplopia and maintains good binocular function.

\section{Discussion}

This report describes a patient with antimetropia, diplopia, and strabismus with tilted disc syndrome. To our knowledge, there are no cases in the literature presenting an antimetropia with tilted disc syndrome.

Tilted disc syndrome is characterized by an oval optic disc with an oblique axis, an inferonasal crescent, situs inversus of the retinal vessels, myopic astigmatism, and visual field defects. Dehghani et $\mathrm{al}^{8}$ evaluated the ocular, refractive, and biometric characteristics in patients with tilted disc syndrome

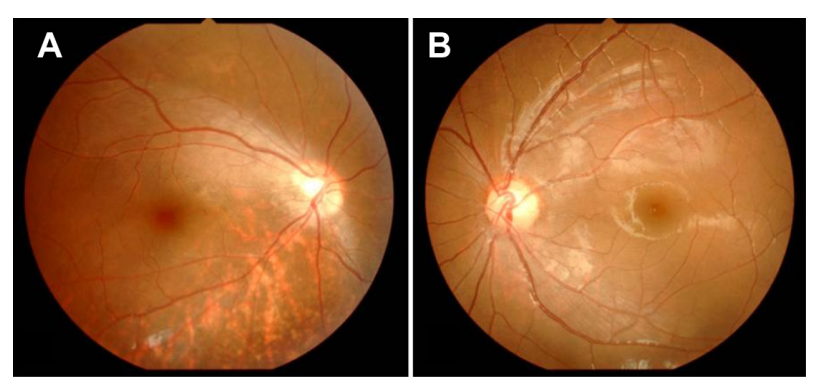

Figure I (A) Right eye fundus photograph shows a tilted disc with an inferior staphyloma. (B) No abnormalities are evident in the left eye. and compared them with a normal population. According to their report, there were no significant differences in spherical equivalent and total astigmatism between groups. However, mean best corrected visual acuity was significantly worse in the tilted disc syndrome patients. Furthermore, the lenticular astigmatism was greater in the syndrome group, whereas the corneal component was greater in controls. The measured biometric features were the same in both groups, except for the lens thickness and lens-axial length factor, which were greater in the tilted disc syndrome group.

Although other biometric data, including anterior chamber depth, lens thickness, vitreous chamber depth, and relative lens position were unavailable in this case, it is likely that the antimetropia was due to elongation of the axial length in unilateral tilted disc syndrome.

A significant degree of antimetropia with strabismus is extremely rare. Richards ${ }^{3}$ showed that motility evaluation revealed monofixation and that a small angle esotropia was common, occasionally accompanied by a vertical element. Additionally, in the same study, ${ }^{3}$ it was demonstrated that a switch in fixation sometimes occurs in strabismus with antimetropia when the preferred, less hyperopic eye evolves into a slightly myopic eye. A patient with compound hyperopic anisometropia most often prefers fixation with the less hyperopic eye and is usually free of diplopia because of the habitual suppression of the more hyperopic eye. However, when the less ametropic hyperopic preferred eye becomes myopic, the patient may switch to the previously suppressed and still hyperopic eye.

Although the previously preferred eye, ocular alignment, and changes in refractive error in this patient were unknown, the possible explanation for his condition is as follows: as the patient did not complain of diminished vision for far and near objects until the initial visit, gradual increasing myopic change in the right eye resulted in diminished vision for distant objects, and as a result of the deteriorated binocular function with the normal ocular alignment, strabismus with diplopia manifested.

Although the current findings are based on a single case, it is suggested that early detection and optical correction might be essential for amblyopia prevention and to attain good binocular function in patients with antimetropia.

Finally, most eyes with tilted disc syndrome reportedly have a good visual prognosis. However, when the upper temporal border of an inferior staphyloma lies across the macula, it is occasionally accompanied by macular complications that may lead to visual loss..$^{5-7}$ Therefore, careful observation is 

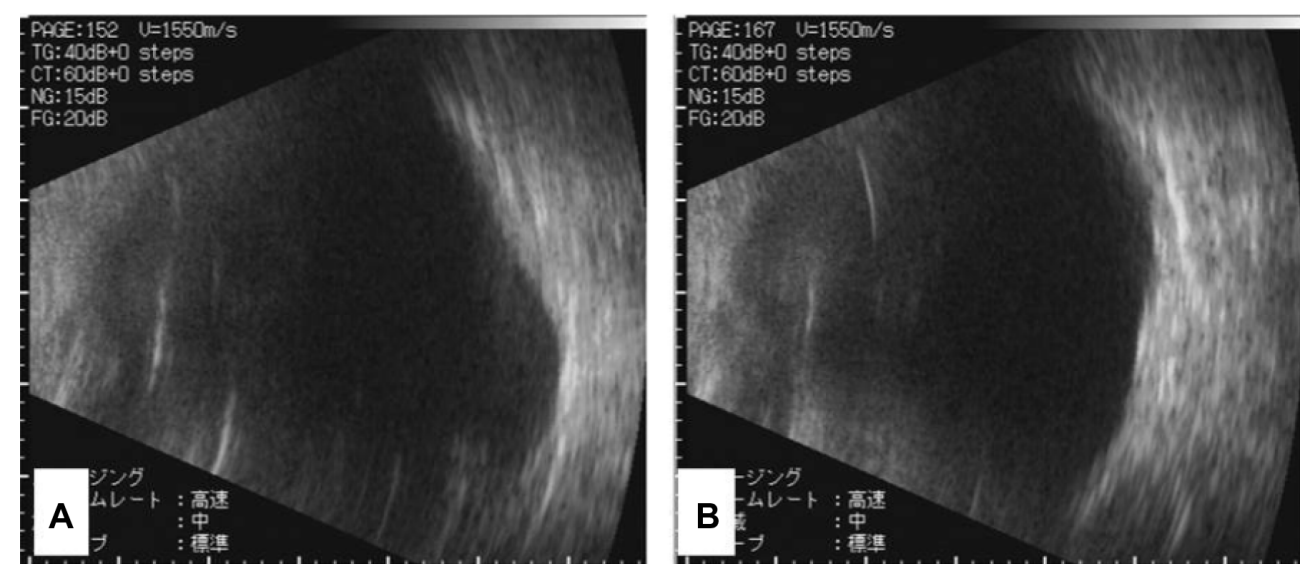

Figure 2 (A) Right eye ultrasonic B-scan echography shows an inferior staphyloma. (B) No abnormalities are evident in the left eye.

also necessary, for the early detection of several types of macular complications, on an inferior staphyloma associated with tilted disc syndrome.

\section{Disclosure}

The author reports no conflicts of interest in this work.

\section{References}

1. Rabin J. An unusual case of antimetropia. Am J Optom Physiol Opt. 1985;62(4):287-291.

2. Hallak J, Yu J. Prevalence of paradoxical anisometropia. J Am Optom Assoc. 1987;58(7):572-576.
3. Richards R. The syndrome of antimetropia and switched fixation in strabismus. Am Orthopt J. 1991;41:96-101.

4. Kunikami K, Choya T, Miyata M, et al. Visual function in antimetropia. Jpn Orthopt J. 2010;39:103-108.

5. Cohen SY, Quentel G, Guiberteau B, Delahaye-Mazza C, Gaudric A. Macular serous retinal detachment caused by subretinal leakage in tilted disc syndrome. Ophthalmology. 1998;105(10):1831-1834.

6. Witmer MT, Margo CE, Drucker M. Tilted optic disks. Surv Ophthalmol. 2010;55(5):403-428.

7. Nakanishi H, Tsujikawa A, Gotoh N, et al. Macular complications on the border of an inferior staphyloma associated with tilted disc syndrome. Retina. 2008;28(10):1493-1501.

8. Dehghani C, Nowroozzadeh MH, Shankar S, Razeghinejad MR. Ocular refractive and biometric characteristics in patients with tilted disc syndrome. Optometry. 2010;81(12):688-694.
Clinical Optometry

\section{Publish your work in this journal}

Clinical Optometry is an international, peer-reviewed, open access journal publishing original research, basic science, clinical and epidemiological studies, reviews and evaluations on clinical optometry. All aspects of patient care are addressed within the journal as well as the practice of optometry including economic and business analyses. Basic and clinical

Submit your manuscript here: http://www.dovepress.com/clinical-optometry-journa

\section{Dovepress}

research papers are published that cover all aspects of optics, refraction and its application to the theory and practice of optometry. The manuscript management system is completely online and includes a very quick and fair peer-review system, which is all easy to use. Visit http://www.dovepress. com/testimonials.php to read real quotes from published authors. 